\title{
Drug prescribing pattern of antifungal drugs for local fungal infections in a tertiary care hospital: MAMC, Agroha
}

\author{
Preety Bansal $^{1 *}$, Seema Baishnab ${ }^{1}$, Ashima Singla ${ }^{2}$ \\ ${ }^{1}$ Department of Pharmacology, Maharaja Agrasen Medical College, Agroha, Haryana, India \\ ${ }^{2}$ Department of Pharmacology, Adesh Institute of Medical Sciences And Research, Bathinda, Punjab, India
}

Received: 17 April 2021

Accepted: 10 May 2021

\author{
*Correspondence: \\ Dr. Preety Bansal, \\ Email: preetybansal137@gmail.com
}

Copyright: $@$ the author(s), publisher and licensee Medip Academy. This is an open-access article distributed under the terms of the Creative Commons Attribution Non-Commercial License, which permits unrestricted non-commercial use, distribution, and reproduction in any medium, provided the original work is properly cited.

\begin{abstract}
Background: Drug utilization research or studies are the powerful exploratory tools to ascertain the role of drugs in the society which refers to the marketing, distribution, prescription and use of drugs with special emphasis on the medical, social and economic consequences. Periodic prescription audit in form of drug utilization study is a way to improve the quality of prescription and promote rational prescribing.

Methods: This was a prospective and an observational study. Prescriptions included all newly diagnosed patients with cutaneous fungal infection of both sexes who attended dermatology OPD. Factors considered were sociodemographic parameters and WHO prescribing indicators.

Results: 1000 prescriptions were analysed of patients between 18 to 65 years of age with cutaneous fungal infections. The average number of drugs per encounter was 3.68. The percentage of drugs prescribed by generic name was $50.33 \%$ and the percentage of drugs prescribed from NLEM was $20.93 \%$.

Conclusions: This study indicates that prescribing practices of drugs in tertiary care hospital can be improved by promoting generic name drug prescribing, prescribing drugs from NLEM and by reducing polypharmacy.
\end{abstract}

Keywords: Fungal infections, Antifungal drugs, WHO prescribing indicators

\section{INTRODUCTION}

Fungal infections of the skin were the fourth most common skin disease in 2010 affecting 984 million people. ${ }^{1}$ There are many antifungal drugs which are used to treat fungal infection. But for effective therapy selection of most appropriate drug for fungal infection is essential. Antifungals in dermatophytes treatment are classified which include itraconazole, fluconazole belongs to triazole group, terbinafine belongs to allylamine respectively. ${ }^{2}$ Antifungal therapy has undergone a tremendous transformation in recent years. ${ }^{3}$

Drug utilization research or studies are the powerful exploratory tools to ascertain the role of drugs in the society which refers to the marketing, distribution, prescription and use of drugs with special emphasis on the medical, social and economic consequences. Periodic prescription audit in form of drug utilization study is a way to improve the quality of prescription and promote rational prescribing. ${ }^{4}$

Prospective DUS involves evaluating the patient's disease and its intended drug therapy before a drug is given. It generally addresses generic substitution, drug, disease contraindications, therapeutic interchange and wrong dosage, improper duration of treatment, clinical abuse and drug allergy. Thus drug utilization studies helps in the understanding of prescription pattern as well as the quality of prescription in terms of rationality, drug interactions. 


\section{Aim and objective}

Aim and objective of current study was to describe demographic characteristics and drugs utilization pattern using core prescribing indicators by WHO.

\section{METHODS}

Current investigation was prospective and an observational study conducted in the dermatology outpatient department of Maharaja Agrasen medical college hospital and research centre for one year from February 2018 to January 2019.

\section{Inclusion criteria}

Inclusion criteria for the current study were patients between 18-65 years of either sex who visited skin and venereal disease department for the first time and were prescribed antifungal drugs.

\section{Exclusion criteria}

Exclusion criteria for the current study were those OPD patients who were admitted in wards of skin and VD department/referred patients to dermatology department by other departments, patients below 18 years and above 65 years, prescriptions without antifungal drugs and patients who were not ready to give written informed consent.

\section{Data collection}

1000 prescriptions were studied and included in the final analysis. Factors analysed were demographic parameters (age and sex), Data related to drugs prescribed were recorded as per WHO core prescribing indicators, i.e. average number drugs per encounter, percentage of drugs prescribed with generics, percentage of encounters with antifungal prescribed, percentage of drugs from NLEM 2015 (National list essential medicine ).

\section{Statistical analysis}

All the data were compiled into microsoft office excel 2010 version and a descriptive statistical analysis was carried out. The results on continuous measurement scale were presented as mean $\pm \mathrm{SD}$ and results on categorical measurement type were presented as simple percentage. Epi info 0.7 software was used for analysis.

\section{RESULTS}

A total of 1000 prescriptions of antifungal drugs were analysed for local fungal infections in between 18 to 65 years of age.

\section{Age wise distribution}

Majority of the patients were from 18 to 65 years of age (47.4\%) followed by $28-37$ years age group (23.7\%) (Figure 1). Less common age group affected were between $48-57$ years $(7.3 \%)$ and 58-65 years age group $(5 \%)$. Mean age and standard deviation was found to be $31.78 \pm 11.88($ mean \pm SD). Out of 1000 participants, 574 male and 426 female were affected with fungal infections. The male to female ratio was 1.34 (Figure 2).

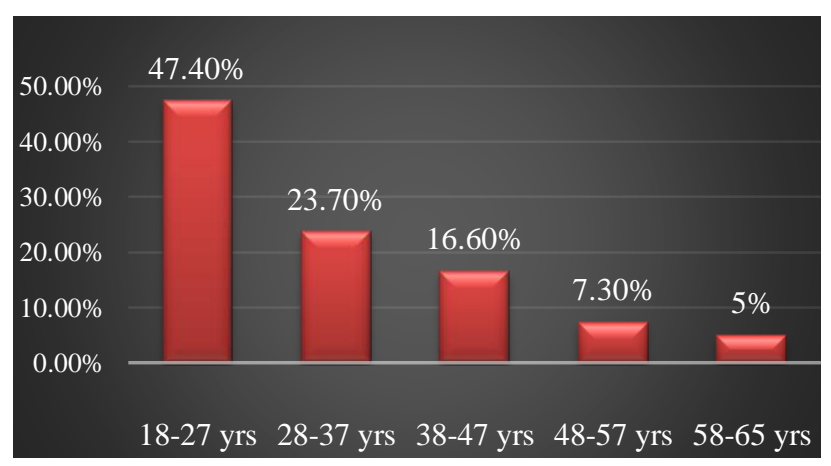

Figure 1: Age based distribution.

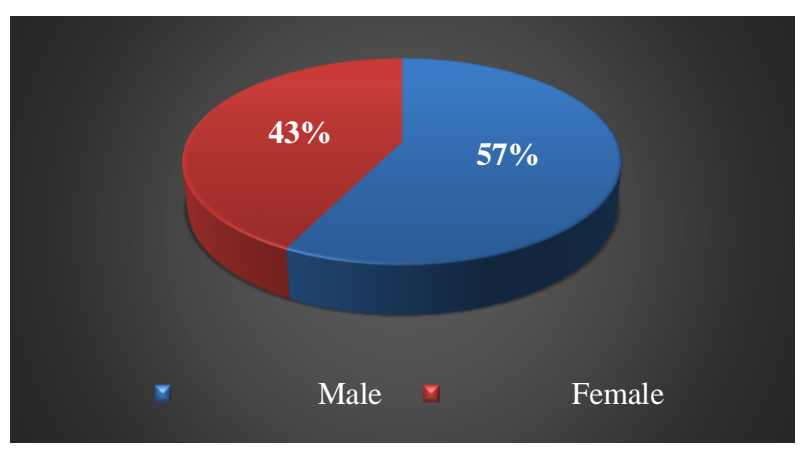

Figure 2: Sex based distribution.

\section{Occupation distribution}

Homemakers $(30.20 \%)$ were most commonly affected with the superficial fungal infection followed by students $(24.50 \%)$ and farmers $(21.10 \%)$. Labourers $(9.70 \%)$ and others $(14.50 \%)$ were less commonly affected (Figure 3 ).

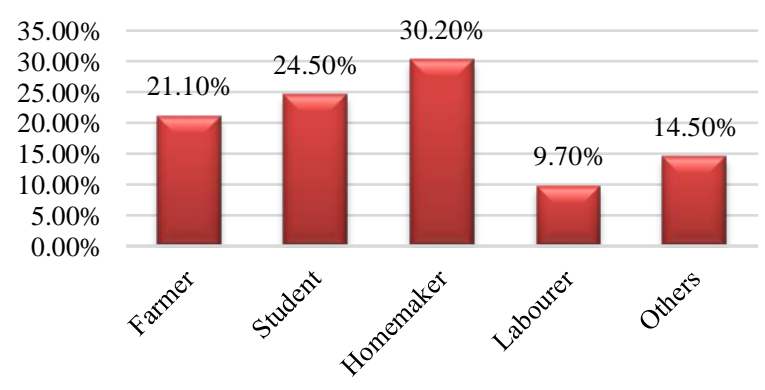

Figure 3: Occupation based distribution. 


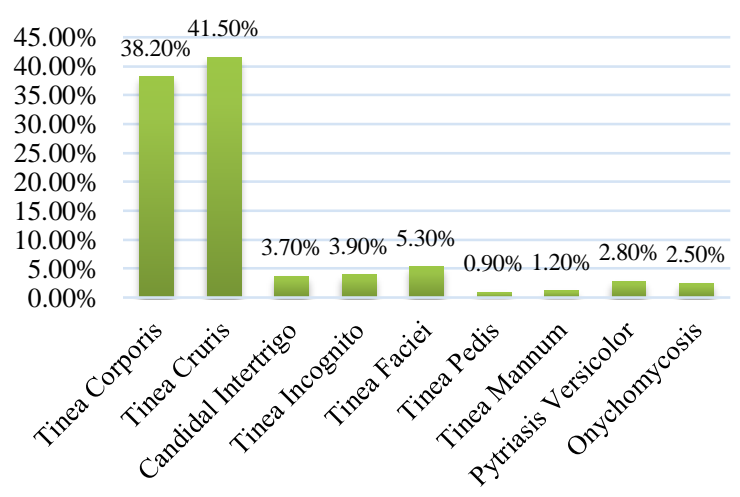

Figure 3: Disease based distribution.

\section{Disease distribution}

Most common infection in study population was tinea cruris $(41.5 \%)$ followed by tinea corporis $(38.20 \%)$. tinea faciei $(5.30 \%)$, tinea incognito $(3.90 \%)$, candidal intertrigo $(3.70 \%)$, pityriasis versicolor $(2.80 \%)$ and onychomycosis $(2.50 \%)$ were less commonly seen in study participants (Figure 4).

\section{WHO prescribing indicators}

Total 1000 prescriptions contained 3683 drugs. Out of these, 2331 drugs were antifungal drugs. The other most commonly co-prescribed drugs were antihistamines. Based on WHO prescribing indicators the average number of drugs per encounter was 3.68 , which was not within the range limit of WHO standard (Table 1). Average number of antifungal prescribed per encounter was 2.33. Average number of systemic antifungal drugs prescribed per encounter was 1 and average number of topical antifungal drugs prescribed per encounter was 1.33 respectively. The percentage of drugs prescribed by generic name was $50.33 \%$ and the percentage of drugs prescribed from NLEM was $20.93 \%$ which were lesser than WHO standard value. No injections were prescribed during the study.

Table 1: WHO prescribing indicators.

Prescribing indicators

Average number of drugs prescribed per encounter

Average number of antifungal prescribed per encounter A verage or percentage

Average number of systemic antifungal drugs prescribed per encounter

Average number of topical antifungal drugs prescribed per encounter

Percentage of encounter with injections

Percentage of drugs prescribed by generic drugs 3.68

Percentage of drugs prescribed from NLEM (2015)

2.33

1

1.33

0

\section{DISCUSSION}

Drug utilization studies focus on factors related to prescribing, dispensing, administering and taking of medication and its associated events like covering the medical and non medical determinants. It also focus on the effects of drug utilization, as well as the studies of how drug utilization relates to the effects of drug use and its advantages or disadvantages. ${ }^{6,7}$

In the present study, $57.40 \%$ of the study subjects were male and $42.60 \%$ were female which shows male preponderance. In a study done by Patil et al showed male were affected $56.86 \%$ followed by the female $43.14 \%$. In George et al study also most commonly male $(51.35 \%)$ were affected followed by female. ${ }^{8,9}$

Dermatophytosis can affect every age group with no specific age group being immune to the infection. In our series, the age of the affected patients ranged from 18 years to 65 years. Although all age groups can be affected, the majority of patients in our study were in the 18 to 27 years age group accounting for $47.4 \%$ of the patients. This age group was closely followed by 28-37 years accounting for $23.7 \%$ of the patients. In a study done by Jain et al and Shukla et al they observed that the most common affected age group was 21-30 years of age which is similar with current study. ${ }^{10,11}$ Homemakers (30.20\%) were most commonly affected followed by students $(24.50 \%)$ and farmers $(21.10 \%)$. Vegda et al conducted study in a tertiary care hospital showed mostly homemakers were affected. ${ }^{12}$ In Andrea et al study the maximum number of patients belong the group of homemakers. ${ }^{13}$ This was followed by students. In current study others group include businessman, serviceman, teachers, photographers, drivers which were least affected. In Vegda et al study the least group affected was serviceman and businessman. ${ }^{12}$

Tinea cruris was the commonest and seen in $41.50 \%$ of the patients followed by tinea corporis which was seen in $38.20 \%$ of the patients. Khosley et al also reported the similar observation in his study as tinea cruris $(55.07 \%)$ followed by tinea corporis $(39.20 \%)$ as the most common clinical pattern. ${ }^{14}$

In current study average number of drugs per encounter was 3.68. Vegada et al conducted a study showed that average 3.39 drugs per encounter were prescribed. ${ }^{12}$ Gopimohan et al study showed average 3.12 drugs per encounter were prescribed. ${ }^{15}$ Patil et al study showed average number of drugs per prescription was $3.27 .^{8}$ This is similar to current study, but according to WHO the 
average number of drugs per encounter was 5.13. Polypharmacy is regarded as a form of over-prescribing. It can lead to poor compliance, drug interactions, and adverse drug reactions, under use of effective treatments, medication errors and increased cost of therapy. Drug interactions due to polypharmacy may lead to inessential hospitalization and increasing the cost of treatment again. ${ }^{16}$

In present study average number of antifungal prescribed per encounter was 2.33 and average numbers of systemic and topical antifungal prescribed per encounter were 1 and 1.33 respectively. Vegada et al study showed that average number of antifungal prescribed per encounter was 2.08. ${ }^{12}$ Average number of systemic antifungal drugs prescribed per encounter was 0.98 and average number of topical antifungal drugs prescribed per encounter 1.10 respectively. Gopimohan et al study showed that average number of antifungal prescribed per encounter was $2 .{ }^{15}$ Average number of systemic and topical antifungal drugs prescribed per encounter were 1 and 1.10 respectively.

In current study the percentage of drugs prescribed by generic name was $50.33 \%$. In Vegada et al study it was $54.33 \% .{ }^{12}$ It is similar to current study. In Patil et al it was $31.1 \% .^{8}$ In Narwane et al study percentage of drugs prescribed by generic name was $16.6 \% .{ }^{16}$ In comparison to these results values, it is found that our study findings are more than these study. According to WHO the percentage of drugs prescribed by generic name is 100 . So in our study generic drug utilization is lesser than the WHO standard value. The percentage of drugs prescribed from NLEM was $20.93 \%$ which was also lesser than the WHO standard value. Kumar et al study showed $23.42 \%$ NLEM drugs prescribed. ${ }^{17}$

\section{CONCLUSION}

Drug utilization study is an effective tool to promote rational and cost-effective drug prescribing. Current study indicates that prescribing practices of drugs in tertiary care hospital can be improved by promoting generic name drug prescribing, prescribing drugs from NLEM and by reducing polypharmacy.

Funding: No funding sources

Conflict of interest: None declared

Ethical approval: The study was approved by the Institutional Ethics Committee

\section{REFERENCES}

1. Hay RJ, Johns NE, Williams HC, Bolliger IW, Dellavalle RP, Margolis DJ, et al. The global burden of skin disease in 2010: An analysis of the prevalence and impact of skin conditions. J Investig Dermatol. 2013;134:1527-34.

2. Sharma HL, Sharma KK. Principles of pharmacology. 2nd ed. Hyderabad: Paras Publications; 2011:796.
3. Murray PR, Rosenthal KS, Pfaller MA. Medical microbiology. 7th ed. Philadelphia: Elsevier; 2013: 631.

4. Deb P, Mohanty I, Slathia I, Verma V. Drug utilisation and self medication pattern of anti-fungal drugs in dermatology outpatient department of a tertiary care hospital. Int $\mathbf{J}$ Basic Clin Pharmacol. 2017;6(9):2189-92.

5. Pathak AK, Kumar S, Kumar M, Mohan L, Dikshit H. Study of drug utilization pattern for skin diseases in dermatology opd of an Indian tertiary care hospital: A prescription survey. J Clin Diagn Res. 2016; 10(2):FC01-05.

6. Strom BL. Pharmacoepidemiology. 4th ed. England: John Wiley \& Sons; 2005:1-15.

7. Lunde PKM, Baksaas I, Halse M, Halvorsen IK, Stromnes B, Oydvin K. The Methodology of drug utilization studies. In: Bergman U, Grimson A, Westerholm B, eds. Europe: WHO Regional Publications, European Series; 2017:8;17-28.

8. Patil A, Dighe D, Kolte S, Jadhav PR, Deshmukh YA. Drug utilization pattern in dermatology outpatient department at a tertiary care hospital in Navi Mumbai. Int J Basic Clin Pharmacol. 2017; 6(3):559-62.

9. George AJ, Godbole D, Mali M, Pawar S. Assessment of etiology pattern and treatment of tinea infections in a tertiary care hospital. Adv Med Dent Health Sci. 2018;1(1):8-11.

10. Jain N, Sharma M, Sharma M, Saxena VM. Spectrum of dermatophytosis in Jaipur. Afr $\mathbf{J}$ Microbiol. 2014;8(3):237-43.

11. Shukla P, Yaqoor S, Shukla V, Garg J, Dar ZP, Haider F. Prevalence of superficial mycosis among outdoor patients in a tertiary care hospital. Natl $\mathbf{J}$ Med Sci. 2013;2(2):19-26.

12. Vegada BN, Karelia BN, Singh AP. Drug utilization study of antifungal agents used in department of skin \& V.D. of a tertiary care teaching hospital. Int J Pharm Sci Rev Res. 2015;34(1):118-21.

13. Andrea C, Pires A, Lobato AM, Regina F, Carneiro O. Clinical, epidemiological, and therapeutic profile of dermatophytosis. An Bras Dermatol. 2014;89(2): 259-65.

14. Koshley V, Halwai AK, Koshley SB, Kurrey PK, Jaiswal S. Treatment pattern of dermatophytosis at the outpatient clinic of a tertiary healthcare hospital of Chhattisgarh, central India. Indian J Clin Exp Dermatol. 2018;4(4):327-30.

15. Gopimohan P, Sudha MJ, Pillai RT, Ramani PT. A study on the prescription pattern of antifungal drugs in the dermatology department of a tertiary care teaching hospital in southern Kerala. Int J Basic Clin Pharmacol. 2019;8(1):100-3.

16. Narwane SP, Patel TC, Shetty YC, Chikhalkar SB. Drug utilization and cost analysis for common skin diseases in dermatology OPD of an Indian tertiary care hospital-A prescription survey. Br J Pharm Res. 2011;1(1):9-18. 
17. Kumar J, Chandra S, Sinha HK. Utilization pattern of drugs among dermatological outpatients in a tertiary care hospital of eastern India. Int J Clin Pharmacol Res. 2016;6(9):297-302.
Cite this article as: Bansal $\mathrm{P}$, Baishnab S, Singla A. Drug prescribing pattern of antifungal drugs for local fungal infections in a tertiary care hospital: MAMC, Agroha. Int J Basic Clin Pharmacol 2021;10:689-93. 